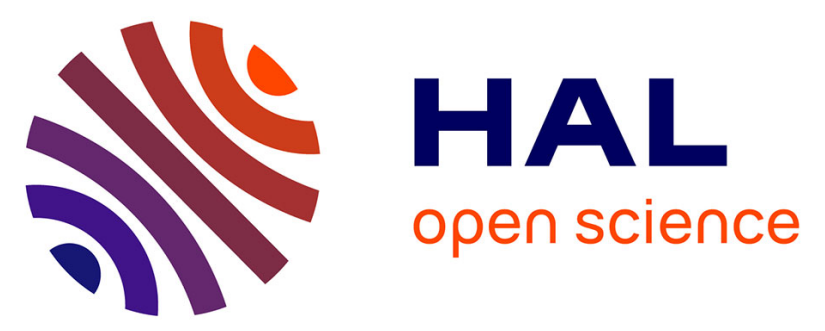

\title{
Impact of the Rome II Pediatric Criteria on the Appropriateness of the Upper and Lower Gastrointestinal Endoscopy in Children
}

Erasmo Miele, Eleonora Giannetti, Massimo Martinelli, Antonella

Tramontano, Luigi Greco, Annamaria Staiano

\section{To cite this version:}

Erasmo Miele, Eleonora Giannetti, Massimo Martinelli, Antonella Tramontano, Luigi Greco, et al.. Impact of the Rome II Pediatric Criteria on the Appropriateness of the Upper and Lower Gastrointestinal Endoscopy in Children. Alimentary Pharmacology and Therapeutics, 2010, 32 (4), pp.582. 10.1111/j.1365-2036.2010.04383.x . hal-00552583

\section{HAL Id: hal-00552583 https://hal.science/hal-00552583}

Submitted on 6 Jan 2011

HAL is a multi-disciplinary open access archive for the deposit and dissemination of scientific research documents, whether they are published or not. The documents may come from teaching and research institutions in France or abroad, or from public or private research centers.
L'archive ouverte pluridisciplinaire HAL, est destinée au dépôt et à la diffusion de documents scientifiques de niveau recherche, publiés ou non, émanant des établissements d'enseignement et de recherche français ou étrangers, des laboratoires publics ou privés. 


\begin{tabular}{l}
\hline Alimentary Pharmacology \\
\hline \& Therapeutics \\
\hline
\end{tabular}

\section{Impact of the Rome II Pediatric Criteria on the Appropriateness of the Upper and Lower Gastrointestinal Endoscopy in Children}

\begin{tabular}{|r|l|}
\hline Journal: & Alimentary Pharmacology \& Therapeutics \\
\hline Manuscript ID: & APT-0019-2010.R1 \\
\hline Manuscript Type: & Original Scientific Paper \\
\hline Domplete List of Authors: & $\begin{array}{l}\text { Miele, Erasmo; University of Naples "Federico II", Department of } \\
\text { Pediatrics } \\
\text { Giannetti, Eleonora; University of Naples "Federico II", Department } \\
\text { of Pediatrics } \\
\text { Martinelli, Massimo; University of Naples "Federico II", Department } \\
\text { of Pediatrics } \\
\text { Tramontano, Antonella; University of Naples "Federico II", } \\
\text { Department of Pediatrics } \\
\text { Greco, Luigi; University of Naples, Dept. of Paediatrics } \\
\text { Staiano, Annamaria; University of Naples "Federico II", Department } \\
\text { of Pediatrics }\end{array}$ \\
\hline Keywords: & $\begin{array}{l}\text { Paediatric gastroenterology < Topics, Endoscopy < Topics, } \\
\text { Functional GI diseases < Disease-based, Colonoscopy < Topics }\end{array}$ \\
\hline
\end{tabular}

\section{今 ScholarONE" \\ Manuscript Central}




\title{
Impact of the Rome II Pediatric Criteria on the Appropriateness of the Upper and Lower Gastrointestinal Endoscopy in Children
}

\section{Erasmo Miele, MD, PhD, Eleonora Giannetti, MD, Massimo Martinelli,_MD, Antonella}

Tramontano, MD, Luigi Greco, MD, PhD and Annamaria Staiano, MD

Department of Pediatrics, University of Naples “Federico II", Italy

Running Head: Rome II Pediatric Criteria and GI Endoscopy in Children

Key words: Functional Gastrointestinal Disorders, Endoscopy, Rome II Criteria, Diagnosis, Pediatrics

\author{
Corresponding author: Annamaria Staiano, MD \\ Department of Pediatrics \\ University of Naples "Federico II" \\ Via S. Pansini, 5 \\ 80131 Naples, Italy \\ Tel. +39.081.7462679 \\ Fax: +39.081.5469811 \\ e-mail: staiano@unina.it
}


Miele et al

2 Abstract
Background: The demand for pediatric Gl endoscopy has increased, resulting in a significant rise in overall costs. Aim: to assess the clinical impact of the Rome II criteria for FGIDs in selecting pediatric patients who underwent Gl endoscopy. Methods: Indications and findings of $\mathrm{Gl}$ endoscopic procedures performed before and after the publication of the Rome II criteria were retrospectively evaluated. Results: Upper GI endoscopy was performed in 1124 children, whereas 500 subjects underwent colonoscopy. Six-hundred-seven (54\%) EGDs were positive, and 517 (46\%) were negative, whereas $306(61.1 \%)$ colonoscopies were positive, and $194(38.9 \%)$ were negative. Of the 1624 procedures, $26 \%$ were considered inappropriate according to the Rome II criteria. Inappropriate procedures decreased significantly after publication of the Rome II criteria (OR, 3.7; 95\% Cl, 1.8-7.5). Of 1202 appropriate GI endoscopies, 502 EGD $(62.7 \%)$ were significantly contributive, compared with only $105(32.5 \%)$ of the 323 inappropriate procedures (OR, 3.5; 95\% Cl, 2.6-4.6;), whereas 265 (65.8\%) colonoscopies were significantly contributive, compared with only 41 (42.3\%) of the 97 inappropriate procedures (OR, 2.6; $95 \% \mathrm{Cl}, 1.6-4.1)$. Conclusions: The use of the criteria for FGIDs makes a significant positive impact in reducing unnecessary pediatric Gl endoscopy.
Deleted: \& Aim

Formatted: Font: Bold Deleted: The aim of our study was 
Miele et al

\section{Introduction}

Functional gastrointestinal disorders (FGIDs) are defined as a variable combination of chronic or recurrent gastrointestinal symptoms unexplained by structural or biochemical abnormalities. In 1997, a pediatric working team met in Rome to standardize the diagnostic criteria for various FGIDs in children. The first pediatric criteria for FGIDs were published in 1999 as the Rome II criteria (1). These criteria were created as a diagnostic tool and as a way to advance empirical research, providing clinicians with a positive approach to treating pediatric patients. Recently, in light of emerging scientific research and on the basis of clinical experience, the Rome II pediatric criteria have been updated and revised. The Rome III pediatric criteria represent an evolution from Rome II and should prove useful for both clinicians and researchers dealing with childhood FGIDs (2, 3).

The demand for gastrointestinal endoscopy has increased in most developed Deleted: pediatric countries, resulting in a significant rise in overall costs for endoscopic procedures_(4). During the past few years, various organizations have tried to develop criteria for selecting patients most likely to benefit from gastrointestinal endoscopy (5). Official recommendations on the appropriate use of endoscopy in adults have been released (므, 7). Although few studies have compared the efficiency of gastrointestinal endoscopy to Deleted: 4

Deleted: 5

Deleted: 6 other diagnostic procedures in pediatric patients, recommendations were issued in 1996 by the North American Society of Pediatric Gastoenterology, Hepatology and Nutrition (NASPGHAN) (8). In addition, a technical report by NASPGHAN concluded that, in the evaluation of chronic abdominal pain "there is little evidence to suggest that use of endoscopy and biopsy in the absence of alarm symptoms has a significant yield of organic disease" (2).

Adult studies suggest, however, that alarm features may not discriminate functional from organic disease (10). There are few studies examining the diagnostic outcomes of 
Miele et al

gastrointestinal endoscopy in children (11). The diagnostic yield of esophagogastroduodenoscopy (EGD) in children with abdominal pain was $3.6 \%$ in the existing literature, but this data was based on studies which were compromised by small simple size, variable findings, selection bias and the use of not standardized diagnostic criteria (11). None of the studies used the Rome II pediatric criteria for functional abdominal pain. Few of them examined the predictive value of blood work obtained prior to endoscopy and none of them analysed the association of alarm symptoms or signs to diagnostic yield (11). To our knowledge, there are no studies evaluating appropriateness

Deleted: 10

and diagnostic yield of colonoscopy in the management of children with gastrointestinal disorders.

The main purpose of this study was to assess the impact of the Rome II pediatric criteria for FGIDs in selecting pediatric patients who underwent upper or lower gastrointestinal endoscopy. The secondary objectives were to evaluate the association of alarm symptoms or signs to diagnostic yield and the predictive value of blood work obtained prior to endoscopy.

\section{Patients and Methods}

The study was a retrospective, single-center, cross-sectional study of 1624 consecutive children who underwent upper or lower Gl endoscopy at the Department of Pediatrics of the University of Naples "Federico II" from January 1998 to December 2006. To avoid repeated measures from patients with multiple exams during the study period, only the patients' first procedure was eligible for the study. No patient was excluded on the grounds of having a concomitant chronic disease.

A chart review was performed on all patients who met inclusion criteria. Procedure note, pathology report, laboratory reports, and history and physical examination performed 
up to 1 month prior to the procedure were considered. For those patients who lacked a qualifying history and physical examination, ICD9 codes were reviewed in the electronic medical record. Clinical information was collected prior to the procedure information to mask the reviewer to the outcome of the endoscopy. A review of laboratory tests, which had been obtained up one month prior to the procedure, included hemoglobin level, erythrocyte sedimentation rate (ESR), C - reactive protein (CRP), albumin and fecal calprotectin. Alarm symptoms or signs were evaluated included involuntary weight loss, deceleration of linear growth, gastrointestinal blood loss, vomiting, chronic severe diarrhea, persistent right upper or right lower quadrant pain (12). Chronic diarrhea was defined as the passage of 3 or more watery stool per day for at least two weeks (13).

Deleted: 11

Deleted: 12

The decision to perform endoscopy was made by the hospital-based pediatric gastroenterologist who evaluated symptoms reported by the parents or family and applied the Rome II pediatric diagnostic criteria after their publication.

Endoscopic examination was carried out using standard, forward-viewing pediatric Olympus endoscopes (Europe GMBH, Hamburg, Germany) by experienced pediatric gastroenterologists (EM, AS). The upper or lower Gl endoscopies were performed in either an endoscopy room or an operating room. Those patients who underwent the procedure in an endoscopy room were sedated, while those in the operating room were put under general anesthesia. The decision between these two modalities was based on patient age, reason for endoscopy, and medical history. Sedation, when used, consisted of midazolam, administered intravenously $(0.1 \mathrm{mg} / \mathrm{kg})$. During the colonoscopy, three biopsies were taken from the ileum and subsequently a minimum of two biopsies was taken from every segment of the colon. In the case of an EGD, biopsies were taken from the duodenum, anthrum, corpus and esophagus.

Endoscopic findings were reported according to internationally accepted terms and definitions whenever possible. Review of the final pathology report provided the data 
Miele et al

source for histologic diagnosis. Endoscopic procedures were considered positive if they had direct impact on treatment (ie, gross abnormalities, clinically relevant biopsy findings such as celiac disease and inflammatory bowel disease). They were considered negative if their findings were normal or showed abnormalities that did not affect treatment, such as non-specific endoscopic findings (e.g., erythema, increase or loss vascularity, pallor) and descriptive histological changes (e.g. reactive changes, edema, mild inflammatory changes) $(14,15)$.

Deleted: 13

Based on the symptoms, endoscopic procedures were considered inappropriate if the Rome criteria had been met and appropriate if they hadn't been met. Two investigators ( $E G$ and $A T$ ), who were unaware of the endoscopic findings judged the appropriateness of the indication of the endoscopic findings, according to the Rome II pediatric criteria. To evaluate the effect of the Rome II pediatric criteria on practices, indications and findings of Gl endoscopic procedures, performed before the publication of the FGIDs, diagnostic criteria were compared with those procedures performed under them (1). The Rome II diagnostic criteria are summarized in Table 1.

Means and medians were calculated for dimensional variables after controlling for normality of distribution. The Student's $t$ test for normally distributed variables and the Mann-Whitney $U$ test and $\chi^{2}$ and Fisher exact tests for categorical variables were used where appropriate.

Logistic regression has been used in order to estimate the probability of positive events occurring in upper as well lower Gl endoscopy. The probability of the event occurring was obtained by the linear combination of the contribution of the following indicator variables which significantly contributed, positively as well as negatively, to the prediction of the event: deceleration of linear growth, gastrointestinal blood los, significant vomiting, persistent right upper or right lower quadrant pain involuntary weight loss, chronic severe diahhrea. The sign of the regression coefficient suggests positive or 
3

4

5

6

7

8

9

10

11 negative contribution: the coefficient can be interpretated as the change in the log odds associated with one-unit in the independent variables. A forward stepwise selection was adopted. Odds ratio and accompanying 95\% C.I. were calculated using maximum likelihood ratio method.

Statistical analysis was carried out using SPSS statistical software package for Windows (13.0, SPSS Inc., Chicago, IL). The study was approved by the Institutional Review Board of the University of Naples "Federico II".

\section{Results}

During the study period, $1916 \mathrm{Gl}$ endoscopic procedures were performed in 1713 patients of which 292 were excluded. Ninety-six were excluded because of repeated endoscopies, 136 because they had undergone incomplete procedures, and 60 were excluded because their data were incomplete. Thus, the present study was based on 1624 procedures, each performed in an individual patient. The patients' mean age was 7.4 years (range: 2 months-18 years; 732 boys and 892 girls). EGD was performed in 1124 children, whereas 500 subjects underwent colonoscopy. Two hundred sixty-nine (23\%) upper Gl endoscopies and 64 colonoscopies (12.8\%) were performed before the September 1999 publication of the Rome II criteria in Gut (1). Table 2 details the indications or symptoms for which endoscopy was performed. Six hundred seven (54\%) EGDs were positive, and 517 (46\%) were negative (155 with normal appearance, and 362 with non-specific endoscopic findings), whereas 306 (61.1\%) colonoscopies were positive, and 194 (38.9\%) were negative (46 with normal appearance and 152 with non-specific endosocopic findings). Diagnoses of the upper and lower GI endoscopies are reported in the Table 3.

Gender and age were not predictors of diagnostic yield $\mathrm{OR}=1,95 \% \mathrm{Cl}, 0.8-1.3$, $\left.x^{2}=0.2, p=0.33 ; O R=1.2,95 \% \mathrm{Cl}, 0.9-1.5, \chi^{2}=0.4, \mathrm{p}=0.54\right)$ (Table 4).
Deleted: of the Lmodels were used to investigate characteristics associated with diagnostic yield while controlling for potential confounding variables. A multivariable logistic regression model was constructed to include variables of interest.
Deleted: (

Deleted: :

Deleted: :

Formatted: Superscript 
Patients with one or more alarm symptoms who underwent EGD did not have significantly better diagnostic yield than those without $(53.4 \%$ vs $56.6 \%, p=0.43)$. All patients who underwent colonoscopy had at least one alarm symptom. Among alarm symptoms, deceleration of linear growth was associated with increased diagnostic yield of EGD (OR, 2.5; $\left.95 \% \mathrm{Cl}, 1.7-3.7 ; x^{2}=21.1 ; \mathrm{p}=0.0001\right)$, whereas gastrointestinal blood loss, vomiting, chronic severe diarrhea and persistent right upper or lower quadrant pain were significantly associated with a negative diagnostic yield of EGD (OR, 0.2; 95\% $\mathrm{Cl}, 0.1-0.3$; $\chi^{2}=45, p=0.0001 ;$ OR, $0.5 ; 95 \% \mathrm{Cl}, 0.4-0.7 ; \chi^{2}=26, p=0.0001 ;$ OR, $0.3 ; 95 \% \mathrm{Cl}, 0.2-0.5 ;$ $\chi^{2}=33, \mathrm{p}=0.001 ; \mathrm{OR}, 0.7 ; 95 \% \mathrm{Cl}, 0.6-0.9 ; \chi^{2}=6.6, \mathrm{p}=0.01$, respectively) (Table .5 ). As regards colonoscopy weight loss, deceleration of linear growth, gastrointestinal blood loss, chronic severe diarrhea and persistent right upper or lower quadrant pain resulted significantly associated with increased diagnostic yield $\left(\mathrm{OR}, 8.4 ; 95 \% \mathrm{Cl}, 5.1-14 ; \chi^{2}=82\right.$, $\mathrm{p}=0.0001 ; \mathrm{OR}, 2 ; 95 \% \mathrm{Cl}, 1.1-3.5 ; \chi^{2}=6.7, \mathrm{p}=0.01 ; \mathrm{OR}, 2.5 ; 95 \% \mathrm{Cl}, 1.5-4 ; \chi^{2}=16$, $p=0.0001 ; O R, 4.6 ; 95 \% \mathrm{Cl}, 3-7 ; \chi^{2}=63, p=0.001 ; O R, 5.5 ; 95 \% \mathrm{Cl}, 3.6-8.6 ; \chi^{2}=64$, $\mathrm{p}=0.01$ respectively).

Laboratory parameters including hematocrit, albumin, ESR, CRP and fecal calprotectin were not predictive of diagnostic yield of EGD $\left(\chi^{2}=0.09, p=0.4 ; \chi^{2}=0.04\right.$, $\left.\mathrm{p}=0.5 ; \chi^{2}=0.003, \mathrm{p}=0.5 ; \chi^{2}=0.2, \mathrm{p}=0.3 ; \chi^{2}=0.3, \mathrm{p}=0.3\right)$. However, we found a predictive value of the diagnostic yield of colonoscopy for hematocrit, CRP and of fecal calprotectin $\left(\chi^{2}=34, \mathrm{p}=0.02 ; \chi^{2}=65, \mathrm{p}=0.001 ; \chi^{2}=56, \mathrm{p}=0.007\right)$.

Of the 1624 procedures, $26 \%$ were considered inappropriate according to the Rome II pediatric criteria. Kappa coefficient between the two investigators resulted 0.91 (95\% Cl: 0.88-0.93; agreement: 0.97; SE: 0.01)

A total of 420 children satisfied the Rome II criteria for the various FGIDs (Table 6). The number of inappropriate procedures as a percentage of the total number of

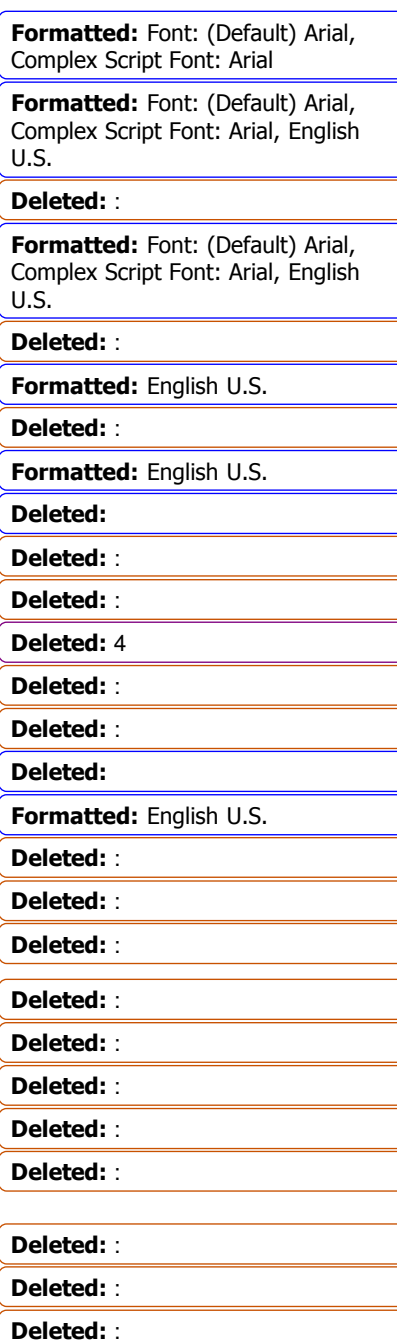


procedures performed decreased significantly (from $38 \%$ to $14 \%$ ) after publication of the Rome II pediatric criteria (OR, 3.7; 95\% CI, 1.8-7.5; $\mathrm{p}<0.001)$. The probability of finding a clinically relevant lesion was significantly higher in appropriate endoscopies compared to those that were inappropriate according to the Rome II pediatric criteria. Of 1202 appropriate upper or lower GI endoscopies (801 EGD; 500 colonoscopies), 502 EGD $(62.7 \%)$ were significantly contributive, compared with only $105(32.5 \%)$ of the 323 inappropriate procedures (OR, 3.5; 95\% Cl, 2.6-4.6; $\mathrm{p}<0.001)$, whereas 265 (65.8\%) colonoscopies were significantly contributive, compared with only $41(42.3 \%)$ of the 97 inappropriate procedures $(\mathrm{OR}, 2.6 ; 95 \% \mathrm{Cl}, 1.6-4.1 ; \mathrm{p}<0.001)$

After the publication of the Rome II pediatric criteria, the proportion of upper GI endoscopy performed for celiac disease was significantly higher than before criteria publication (42.9\% vs $\left.21.4 \% ; \chi^{2}=123 ; \mathrm{p}=0.00001\right)$; no significant difference was observed in the proportion of the procedures performed for peptic ulcer disease $(21.7 \%$ vs $20.6 \%$; $\chi^{2}=0.18 ; \mathrm{p}=0.6$; whereas a significant decrease in the proportion of negative upper GI endoscopy was found $\left(56.8 \%\right.$ vs $\left.36.4 \% ; \chi^{2}=44.9 ; \mathrm{p}=0.00001\right)$. A significant increase in the proportion of lower GI endoscopy for inflammatory bowel disease (IBD) was observed when performed under the Rome II pediatric criteria (22.9\% vs $\left.63.9 \% ; \chi^{2}=38 ; p=0.00001\right)$. Because of the difference in distribution, we also found a significant decrease in the proportion of lower endoscopy performed for GI polyps (18.5 vs 7.3\%; $\chi^{2}=7.68 ; \mathrm{p}=0.051$ ), as well as a significant decrease in the proportion of negative colonoscopies $(58.5 \%$ vs $\left.28.7 \% ; \chi^{2}=20 ; p=0.00006\right)$

To determine which alarm symptoms were significant predictors of diagnostic yield exploratory multivariate conditional logistic regression was conducted in SPSS. Data were screened for predictors as involuntary weight loss, deceleration of linear growth, gastrointestinal blood loss, vomiting, chronic severe diarrhea, persistent right upper or right

\begin{tabular}{|l|}
\hline Deleted: (Table 5). \\
\hline $\begin{array}{l}\text { Formatted: Indent: First line: } \\
35.45 \mathrm{pt}\end{array}$ \\
\hline Deleted: mean rate \\
\hline Formatted: Superscript \\
\hline Deleted: $95 \%$ Cl: -30.1 to $-12.7 ;$ \\
p=0.004 \\
\hline Deleted: mean rate \\
\hline Deleted: $95 \%$ Cl: -11.5 to $13.6 ;$ \\
p=0.84 \\
\hline Deleted: mean rate \\
\hline Deleted: \\
\hline Deleted: \\
\hline Deleted: $95 \%$ Cl: 1.3 to $4 ; \mathrm{p}=0.006$ \\
\hline Deleted: (Figure 1 ) \\
\hline Deleted: mean rate \\
\hline Deleted: $95 \%$ Cl: -58.6 to $-23.2 ;$ \\
p=0.001 \\
\hline Deleted: mean rate \\
\hline Deleted: $95 \%$ Cl: 0.0 to $22.4 ; p=0.05$ \\
\hline Deleted: mean rate \\
\hline Deleted: $95 \%$ Cl: 1.9 to $6 ; \mathrm{p}<0.001$ \\
\hline
\end{tabular}


Miele et al

1

2 3
Deleted: After adjusting for all variables, deceleration

Deleted: group an increased diagnostic yield of EGD, while vomiting, gastrointestinal blood loss (hematemesis, hematochezia, occult lower Gl bleeding) and persistent right upper or right lower quadrant pain predicted a negative diagnostic yield of EGD. As regards colonoscopy, involuntary weight loss, chronic diarrhea, persistent right upper or right lower quadrant pain and gastrointestinal blood loss (hematochezia, occult lower Gl bleeding) remained independently associated with an increased diagnostic yield (Table 그).
Deleted: was independently

correlated with

Deleted: 6 
Miele et al

\section{Discussion}

Gl endoscopy is an essential tool for the evaluation of gastrointestinal disorders in children. Upper and lower endoscopic procedures may be useful if the physician suspects organic pathology, such as inflammatory bowel disease, allergic/eosinophilic gastrointestinal disease, or peptic ulcer disease. These disorders may also present with additional alarm symptoms or signs such as involuntary weight loss, growth failure, gastrointestinal bleeding, chronic diarrhea, unexplained fever, vomiting, or family history of inflammatory bowel disease (9). A recent systematic review demonstrated that the diagnostic yield of EGD in children with unexplained abdominal pain is low, however existing studies are insufficient. The effect of EGD on change in treatment, quality of life, improvement of abdominal pain, and cost-effectiveness is unknown. The predictors of significant findings are unclear (11).

A retrospective study suggested that colonoscopy is the investigative method of choice in children with prolonged rectal bleeding. In patients presenting with accompanying complaints such as abdominal pain or diarrhea, it is advisable to perform ileocolonoscopy combined with EGD. This combines a high diagnostic yield with a safe procedure (16).

Standardized symptom-based criteria were introduced in 1999 with the publication of the Rome II criteria for FGIDs in children (1). Since their publication, the Rome II criteria have been used to assess the prevalence of FGIDs in community settings $(17,18)$ and have served as selection criteria in laboratory studies of pediatric FGIDs (19). Several empirical studies have used the Rome II criteria to estimate the rates of various FGIDs among children with primary symptoms of abdominal pain (20-22).

To our knowledge, this is the first study examining the appropriate use of upper and lower gastrointestinal endoscopy in children using the Rome II pediatric criteria (1). A 
retrospective design was used since one of our objectives was to compare the periods before and after publication of the Rome II pediatric criteria, and this is why we did not apply the Rome III criteria published in 2006 (2). A potential source of error inherent in the retrospective design of the present study could be that some of the patients included may have had symptoms that were not recorded in the medical charts.

In this study, the overall yield was $54 \%$ for EGD and $61.1 \%$ for colonoscopy, similar to what others have found in pediatric and adult series, with celiac disease $(53.3 \%)$, reflux esophagitis (25.9\%), H. Pylori infection (13.7\%) and inflammatory bowel disease (43.4\%) being the most frequent findings $(23-25)$.

After the Rome II pediatric criteria were instituted, the proportion of EGDs performed for celiac disease significantly increased and the presentation has changed. According to previous studies, an increasingly large proportion of children are presenting with non-gastrointestinal symptoms, with almost one in four children being diagnosed by targeted screening (26).

According to a previous pediatric study, IBD was the most common cause in children referred for colonoscopy both before and after the institution of Rome II pediatric criteria (16). This finding confirms the rise in incidence of IBD in childhood (27).

The probability of the endoscopic detection of a clinically relevant finding was higher in those examinations judged as appropriate compared with those deemed inappropriate, according to the Rome II pediatric criteria. However, the low specificity of the Rome II criteria could be indicated by the presence of patients who underwent an appropriate procedure that resulted in a negative finding, as well as by the presence of those patients who underwent an inappropriate endoscopic procedure that resulted in a positive finding (1). By comparing endoscopic procedures performed before the publication of the diagnostic criteria with those procedures performed after its publication, we found that the Rome criteria significantly reduced the proportion of negative endoscopies. Nevertheless,

\begin{tabular}{l} 
Deleted: 22 \\
\hline Deleted: 24 \\
\hline Deleted: rate
\end{tabular}

Deleted: 25

Deleted: 15

Deleted: 26

Deleted: rate 
2

3

4

5

6

7

8

9

10

11 the value of a negative endoscopy should not be overlooked, as it can influence the subsequent management of the patients, and allows unnecessary therapies to be excluded. In a previous study, $67 \%$ of the negative endoscopies in adult patients were judged to have influenced patient management (28).

The mean number of $\mathrm{Gl}$ endoscopies was 166.5 per year before Rome II criteria publication, while it increased to 236 per year after publication of the diagnostic criteria. This data could be explained by several factors. The higher number of procedures could be due to an increased visibility of our Gl endoscopy centre. However, the number of inappropriate endoscopies significantly decreased, according to the hypothesis that primary care physicians may be using Rome II pediatric criteria to filter their referrals. During the study period, no systemic/procedural changes occurred that may have resulted in improved appropriateness of endoscopy over time, except from experience of pediatric gastroenterologists.

The role of alarm symptoms in predicting endoscopic findings is still controversial. Alarm symptoms are traditionally thought to be associated with organic disease (10). $A$ technical report by the American Academy of Pediatrics and NASPGHAN suggested that alarm symptoms should be used to screen children for endoscopy (Evidence D) (9). In contrast, Ashorn and Maki noted that endoscopic abnormalities in their patients did not correlate with the symptoms associated with chronic abdominal pain (29). In addition, a recent study by Thakkar et al found that several alarm symptoms other than vomiting were not significantly predictive of diagnostic yield (30). In our cohort, alarm symptoms (apart from deceleration of linear growth) were predictive of decreased diagnostic yield. On the basis of these results, alarm symptoms seem to be inaccurate and should not be used for deciding who to select for EGD among pediatric patients with upper Gl symptoms. However, our retrospective study has the potential for recall bias that may result in overestimation of the prevalence of "alarm" symptoms prior to endoscopy. The situation
Deleted: 27

Formatted: Indent: First line: 0 pt

Deleted: 8

Deleted: 28

Formatted: Font: Not Italic

Deleted: 29 
Miele et al

regarding lower gastrointestinal pathology looks more promising _(10, $\underline{31})$. In addition, laboratory parameters including hematocrit, albumin, ESR, C-reactive protein (CRP) and fecal caprotectin were not predictive of EGD diagnostic yield, whereas a predictive value of ESR, CRP and fecal calprotectin has been observed for colonoscopy in previous pediatric studies (32-34).

In conclusion, this is the first pediatric, retrospective, observational study, evaluating the impact of the Rome II pediatric criteria on the appropriateness of GI endoscopy. The study finds that the use of the criteria for FGIDs makes a significant positive impact in reducing unnecessary $\mathrm{Gl}$ endoscopic procedures, improving the diagnostic yield and the cost-effectiveness of pediatric endoscopy. However, further refinement and clarification of the Rome pediatric criteria may be needed to improve diagnostic agreement. Further steps are required to update and standardize the guidelines for gastrointestinal pediatric endoscopy and to promote educational programs for pediatric gastroenterologists. 
1

2

3

4

5

6

7

8

9

\section{References}

1. Rasquin-Weber A, Hyman PE, Cucchiara S, Fleisher DR, Hyams JS, Milla PJ, Staiano A. Childhood functional gastrointestinal disorders. Gut 1999;45(Suppl 2): $1160-1168$.

2. Hyman PE, Milla PJ, Benninga MA, Davidson JP,Fleisher DF, and Taminiau J. Childhood Functional Gastrointestinal Disorders: Neonate/Toddler. Gastroenterology 2006;130:1519-1526

3. Rasquin A, Di Lorenzo C, Forbes D, Guiraldes E, Hyams JS, Staiano A, and Walzer LS. Childhood Functional Gastrointestinal Disorders: Child/Adolescent. Gastroenterology 2006;130:1527-1537

4. Hassan C, Bersani G, Buri L, et al. Appropriateness of upper-Gl endoscopy: an Italian survey on behalf of the Italian Society of Digestive Endoscopy. Gastrointest Endosc. 2007 May;65(6):767-74.

5. Burnand B, Harris JK, Wietlisbach V, et al. Use, appropriateness, and diagnostic yield of screening colonoscopy: an international observational study (EPAGE). Gastrointest Endosc 2006;63:1018-26.

6. American Society for Gastrointestinal Endoscopy. Appropriate use of gastrointestinal endoscopy. Gastrointest Endosc 2000; 52:831-837.

7. Axon AT, Bell GD, Jones RH, et al. Guidelines on appropriate indications for upper gastrointestinal endoscopy Working Party of the Joint Committee of the Royal College of Physicians of London, Royal College of Surgeons of England, Royal College of Anaestesists, Association of Surgeons, the British Society of Gatsroenterology, and the Thoracic Society of Great Britain. BMJ 1995; 310: 853856.

8. Squires RH jr, Colletti RB. Indications for Pediatric Gastrointestinal Endoscopy: a medical position statement of the North American Society for Pediatric Gastroenterology and Nutrition. J Pediatr Gastroenterol Nutr 1996; 23: 107-u0.

9. Di Lorenzo C, Colletti RB, Lehmann HP, et al. Chronic Abdominal Pain in Children: a Technical Report of the American Academy of Pediatrics and the North American Society for Pediatric Gastroenterology, Hepatology and Nutrition. J Pediatr Gastroenterol Nutr 2005; 40: 245-261.

10. Hammer J, Eslick GD, Howell SC, et al. Diagnostic yield of alarm features in irritable bowel syndrome and functional dyspepsia. Gut 2004; 53: 666-672.

11. Thakkar K, Gilger MA, Shulman RJ, et al. EGD in children with abdominal pain: a systematic review. Am J Gastroenterol 2007; 102: 654-661.

12. American Society for Gastrointestinal Endoscopy and North American Society for Pediatric Gastroenterology, Hepatology and Nutrition. Modifications in endoscopic practice for pediatric patients Gastrointest Endosc 2008; 67: 1-9.12.

13. Bhutta ZA, Ghishan F, Lindley K, Memon IA, Mittal S, Rhoads JM; Commonwealth Association of Paediatric Gastroenterology and Nutrition. Persistent and chronic diarrhea and malbsorption: Working Group report of the second World Congress of Pediatric Gastroenterology, Hepatology, and Nutrtition. J Pediatr Gastroenterol Nutr 2004; 39: S711-716

14. Hassall E. Macroscopic versus microscopic diagnosis of reflux esophagitis: erosions or eosinophils? J Pediatr Gastroenterol Nutr. 1996;22:321-5.

15. Rudolph CD, Mazur LJ, Liptak GS, et al. North American Society for Pediatric Gastroenterology and Nutrition. Guidelines for evaluation and treatment of gastroesophageal reflux in infants and children: recommendations of the North American Society for Pediatric Gastroenterology and Nutrition. J Pediatr Gastroenterol Nutr. 2001;32:S1-31.
Formatted: Italian Italy Formatted: Bullets and Numbering 
16. de Ridder L, van Lingen AV, Taminiau J AJM and Benninga MA. Rectal bleeding in children: endoscopic evaluation revisited. Eur J Gastroenterol Hepatol 2007; 19: 317-320.

17. Miele $E$, Simeone $D$, Marino $A$, et al Functional gastrointestinal disorders in children: an Itralian prospective study. Pediatrics 2004; 114: 73-78.

18. Uc A, Hyman PE, Walker LS. Functional gastrointestinal disorders in African American children in primary care. J Pediatr Gastroenterol Nutr 2006; 42: 270-274.

19. Faure C, Wieckowska A. Somatic referral of visceral sensations and rectal senosy threshold for pain in children with functional gastrointestinal disorders. J Pediatr 2007; 150: 66-71.

20. Walker LS, Lipani TA, Greene JW, et al. Recurrent abdominal pain : symptom subtypes based on the Rome II criteria for pediatric functional gastrointestinal disorders. J Pediatr Gastroenterol Nutr 2004; 38: 187-191.

21. Caplan A, Walker LS, Rasquin A. Validation of the pediatric Rome II criteria for functional gastrointestinal disorders using the questionnaire on pediatric gastrointestinal symptoms. J Pediatr Gastroenterol Nutr 2005; 41: 3105-3116.

22. Shurman JV, Friesen CA, Danda CE, et al. Diagnosing functional abdominal pain with the Rome II criteria: parent, child, and clinician agreement. $J$ Pediatr Gastroenterol Nutr 2005;41: 291-295.

23. Jantchou P, Schirrer J, Bocquet. Appropriateness of Upper Gastrointestinal Endoscopy in Children: A Retrospective Study. J Pediatr Gastroenterol Nutr 2007; 44: 440-445.

24. Rossi A, Bersani G, Ricci G, et al, ASGE guidelines for the appropriate use of upper endoscopy: association with endoscopic findings. Gastrointestinal Endosc 2002; 56: 714-719

25. Manes G, Balzano A, Marone P, Lionello M, Mosca S. Appropriateness and diagnostic yield of upper gastrointestinal endoscopy in an open-access endoscopy system: a prospective observational study based on the Maastricht guidelines. Aliment Pharmacol Ther 2002; 16: 105-110.

26. M Ravikumara, D P Tuthill and H R Jenkins. The changing clinical presentation of coeliac disease. Arch. Dis. Child 2006;91;969-971.

27. Castro M, Papadatou B, Baldassarre M, Balli F, et al Inflammatory Bowel disease in children and adolescents in Italy: Data from the peiatric national IBD register (1996-2003). Inflamm Bowel Dis 2008; 14: 1246-1252.

28. Naji SA, Brunt PW, Hagen S, Mowat NAG, Russell IT, Sinclair TS, tang TMH. Improving the selection of patients for upper gastrointestinal endoscopy. Gut 1993; 34: 187-191.

29. AshornM, Maki M. Upper gastrointestinal endoscopy in recurrentabdominal pain of childhood. J Pediatr Gastroenterol Nutr 1993;16:273-7.

30. Thakkar K, Chen L, Tatevian N, Shulman RJ, McDuffie A, Tsou M, Gilger MA, ElSerag HB. Diagnostic yield of oesophagogastroduodenoscopy in children with abdominal pain. Aliment Pharmacol Ther. 2009 Sep 15;30(6):662-9. Epub 2009 Jul 2.

31. de Riider L, van Lingen AV, Taminau J, Benninga M. Rectal bleeding in children: endoscopic evaluation revisited. Eur J Gastroenterol Hepatol 2007; 19: 317-320.

32. Boyle JT. Recurrent abdominal pain: an update. Pediatr Rev 1997;18:310-20

33. Khan K, Schwarzenberg SJ, Sharp H, Greenwood D, Weisdorf-Schindele S. Role of serology and routine laboratory tests in childhood inflammatory bowel disease. Inflamm Bowel Dis. 2002;8:325-9. 
Miele et al

34.Berni Canani R, Rapacciuolo L, Romano MT, Tanturri de Horatio L, et al. Diagnostic value of faecal calprotectin in paediatric gastroenterology clinical practice. Dig Liver Dis 2004; 36:467-70. 
Miele et al

Deleted: Table 1. FGIDs: Rome II Diagnostic Criteria 
Miele et al

1

3

4

5

6

7

8

9

10

11

12

13

14

15

16

17

18

19

20

21

22

23

24

25

26

27

28

29

30

31

32

33

34

35

36

37

38

39

40

41

42

43

44

45

46

47

48

49

50

51

52

53

54

55

56

57

58

59

60
Table 2. Indications or Symptoms for Upper and Lower Gastrointestinal Endoscopy

Deleted:

I
Failure to thrive

Unexplained Weight loss

Dysphagia

Recurrent abdominal pain

Vomiting/Regurgitation

Bleeding from GI tract

Chronic diarrhea

Anemia

Suspected esophageal varices

Celiac disease

* More than one indication or symptom was reported in some subjects
All Subjects

n. 1624

$\begin{array}{llllll}N & (\%) & N & (\%) & N & (\%)\end{array}$

$\begin{array}{llllll}36 & (10.8) & 121 & (9.3) & 157 & (9.6) \\ 92 & (27.6) & 392 & (30.3) & 484 & (29.8) \\ 74 & (22.2) & 266 & (20.6) & 340 & (20.9) \\ 236 & (70.8) & 572 & (44.3) & 808 & (49.7) \\ 132 & (39.6) & 189 & (14.6) & 321 & (19.7) \\ 99 & (29.7) & 436 & (33.7) & 535 & (32.9) \\ 88 & (26.4) & 323 & (25.1) & 411 & (25.3) \\ 32 & (9.6) & 152 & (11.7) & 184 & (11.3) \\ 19 & (5.7) & 78 & (6.0) & 97 & (5.8) \\ 30 & (9) & 376 & (29.1) & 406 & (25)\end{array}$


Miele et al

Table 3. Diagnoses and appropriateness according to the Rome II criteria of Upper and Lower Gastrointestinal Endoscopy

\begin{tabular}{|c|c|c|c|c|c|}
\hline \multicolumn{6}{|c|}{ EsophagoGastroDuodenoscopy } \\
\hline & & $\begin{array}{l}\text { Subj } \\
\text { n. } 60\end{array}$ & $\begin{array}{l}\text { ts } \\
\%)\end{array}$ & $\begin{array}{l}\text { Appropriate } \\
\text { n. } 504 \text { (83) }\end{array}$ & $\begin{array}{l}\text { Inappropriate } \\
\text { n. } 103(17)\end{array}$ \\
\hline \multicolumn{2}{|c|}{$\begin{array}{l}\text { Celiac disease } \\
\text { Reflux esophagitis } \\
\text { H. Pylori infection } \\
\text { Eosinophilic Esophagitis } \\
\text { Focal gastritis or duodenal inflammation } \\
\text { Crohn's disease }\end{array}$} & $\begin{array}{l}325 \\
157 \\
83 \\
25 \\
12 \\
5\end{array}$ & $\begin{array}{l}(53.5) \\
(25.9) \\
(13.7) \\
(4.1) \\
(2) \\
(0.8)\end{array}$ & $\begin{array}{l}301(92.6) \\
109(69.4) \\
61(73.5) \\
18(72) \\
9(75) \\
4(80)\end{array}$ & $\begin{array}{l}24(7.4) \\
48(31.6) \\
22(26.5) \\
7(28) \\
3(25) \\
1(20)\end{array}$ \\
\hline \multicolumn{6}{|l|}{ Colonoscopy } \\
\hline & & \multicolumn{2}{|c|}{$\begin{array}{l}\text { Subjects } \\
\text { n. } 306(\%)\end{array}$} & $\begin{array}{l}\text { Appropriate } \\
\text { n. } 265(86.6)\end{array}$ & $\begin{array}{l}\text { Inappropriate } \\
\text { n. } 41(13.4)\end{array}$ \\
\hline \multicolumn{2}{|l|}{$\begin{array}{l}\text { Inflammatory Bowel Disease } \\
\text { Ulcerative Colitis } \\
\text { Crohn's Disease } \\
\text { Indeterminate Colitis }\end{array}$} & \multicolumn{2}{|c|}{$133(43.4)$} & $122(91.7)$ & $11(8.3)$ \\
\hline \multicolumn{2}{|l|}{$\begin{array}{l}\text { Polyps } \\
\text { Allergic colitis } \\
\text { Infectious } \\
\text { Lymphonodular hyperplasia } \\
\text { Eosinophilic Colitis } \\
\text { Focal colitis }\end{array}$} & $\begin{array}{l}40 \\
30 \\
6 \\
39 \\
18 \\
40\end{array}$ & $\begin{array}{l}(13) \\
(9.8) \\
(2) \\
(13) \\
(5.8) \\
(13)\end{array}$ & $\begin{array}{l}34(85) \\
25(83.3) \\
6(100) \\
32(82.1) \\
15(83.3) \\
31(77.5)\end{array}$ & $\begin{array}{l}6(15) \\
5(16.7) \\
0(0) \\
7(17.9) \\
3(16.7) \\
9(22.5)\end{array}$ \\
\hline
\end{tabular}


Miele et al

1

2

3

4

5

6

7

8

9

10

11 12

13

14

15

16

17

18

19

20

21

22

23

24

25

26

28

29

30

31

32

33

34

35

36

37

38

39

40

41

42

43

44

45

46

47

48

49

50

51

52

53

54

55

56

57

58

59

60

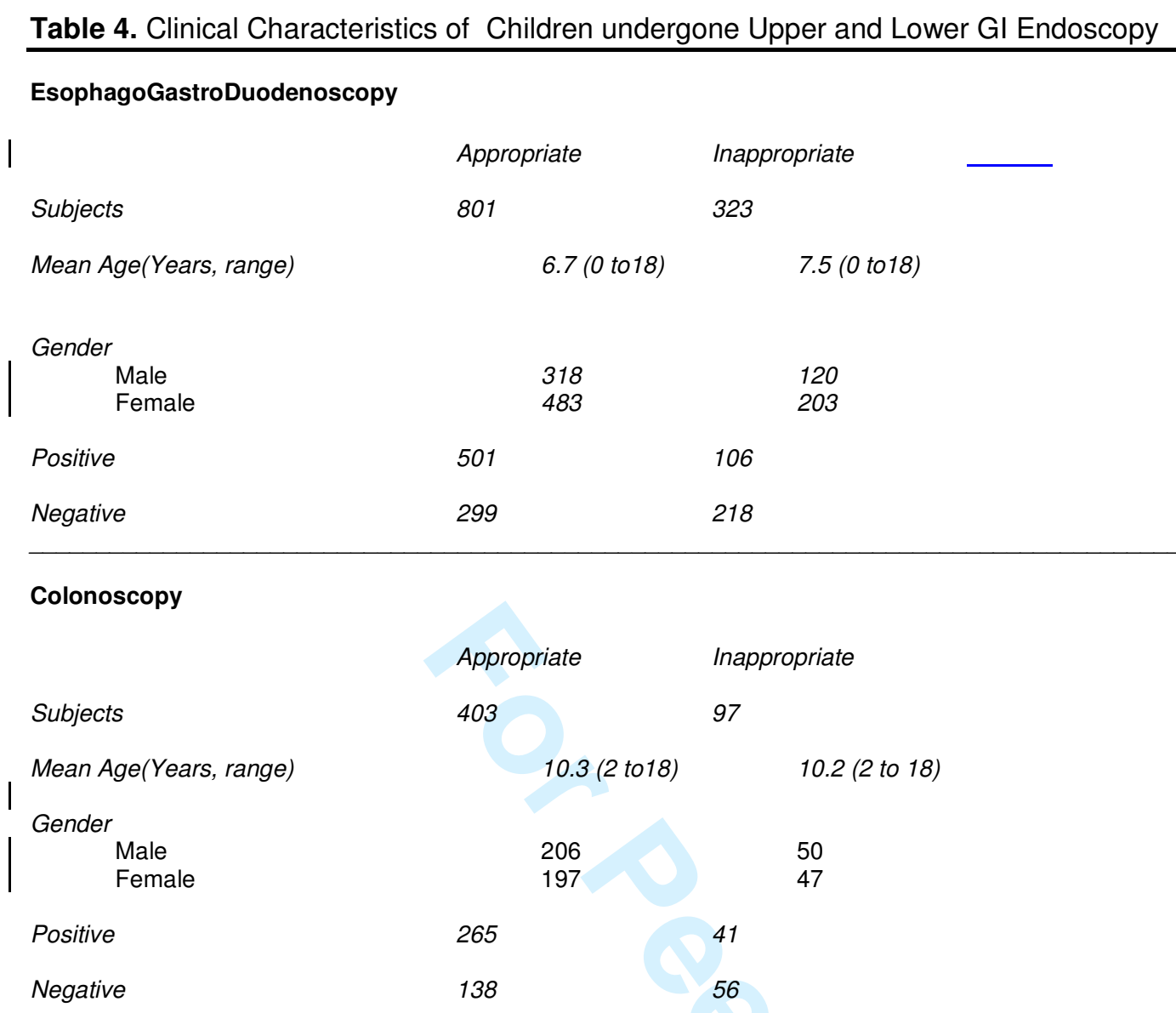


Miele et al

Table 5 . Diagnostic Yield of Upper and Lower Gastrointestinal Endoscopy for Alarm Symptoms ${ }^{\star}(8)$.

\begin{tabular}{|c|c|c|c|c|c|c|}
\hline & \multicolumn{2}{|c|}{ Upper Gl Endoscopy } & \multicolumn{4}{|c|}{ Coolonoscopy } \\
\hline \multicolumn{7}{|l|}{ Subjects } \\
\hline \multicolumn{7}{|c|}{ Any Alarm Symptom } \\
\hline Present & $491(80.9)$ & $428(83)$ & 0.43 & $222(72.7 \%)$ & $385(26.3 \%)$ & NA \\
\hline Absent & $116(19.1)$ & $89(17)$ & & & & \\
\hline \multicolumn{7}{|l|}{ Weight loss } \\
\hline Present & $164(27)$ & $143(27.6)$ & 0.73 & $153(50)$ & $21(10.8)$ & 0.0001 \\
\hline Absent & $443(73)$ & $374(72.4)$ & & $153(50)$ & $173(89.2)$ & \\
\hline \multicolumn{7}{|c|}{ Deceleration of linear growth } \\
\hline Present & $96(15.8)$ & $36(7)$ & 0.0001 & $52(17 \%)$ & $19(10)$ & 0.01 \\
\hline Absent & $511(84.2)$ & $481(93)$ & & $254(83)$ & $175(90)$ & \\
\hline \multicolumn{7}{|c|}{ Gastrointestinal blood loss } \\
\hline Present & $29(4.8)$ & 89 (17.2) & 0.0001 & $267(87.5)$ & $150(77.7)$ & 0.0001 \\
\hline Absent & $578(95.2)$ & $428(82.8)$ & & $39(12.5)$ & $44(22.3)$ & \\
\hline \multicolumn{7}{|l|}{ Significant vomiting } \\
\hline Present & $164(27)$ & $214(41.4)$ & 0.0001 & & & \\
\hline Absent & $443(73)$ & $303(58.6)$ & & & & \\
\hline \multicolumn{7}{|c|}{ Chronic severe diarrhea, } \\
\hline Present & $38(6.3)$ & $89(17.2)$ & 0.0001 & $216(70.8)$ & $68(22.2)$ & 0.001 \\
\hline Absent & $569(93.7)$ & $428(82.8)$ & & $90(29.2)$ & $238(77.8)$ & \\
\hline \multirow{2}{*}{\multicolumn{7}{|c|}{$\begin{array}{l}\text { Persistent right upper or } \\
\text { right lower quadrant pain }\end{array}$}} \\
\hline & & & & & & \\
\hline Present & $308(50.8)$ & $302(58.6)$ & 0.01 & 267 (87.5) & $107(55.5)$ & 0.0001 \\
\hline Absent & $299(49.2)$ & $215(41.4)$ & & 39 (12.5) & $87(44.5)$ & \\
\hline
\end{tabular}

Deleted: 4

Formatted: English U.S.

${ }^{*}$ More than one finding was reported in some subjects 
Table 7. Potential Predictors Associated with Diagnostic Yield of EGD and Colonoscopy in a Multivariate Analysis

\begin{tabular}{|c|c|c|c|c|}
\hline & \multirow{2}{*}{$\begin{array}{l}\text { Regression } \\
\text { coefficient }\end{array}$} & \multirow[t]{2}{*}{ Odds Ratio } & \multirow[t]{2}{*}{$95 \% \mathrm{Cl}$} & Criteriaף \\
\hline$E G D$ & & & & $\begin{array}{l}\text { Disorder } \\
\text { Studied \% Among of . \% of } \\
\text { Children Population. FGIDsף }\end{array}$ \\
\hline Deceleration of linear growth & 0.17 & 1.24 & $1.16-1.32$ & I \\
\hline Gastrointestinal blood loss & -0.15 & $0.8 \underline{5}$ & $0.78-0.93$ & $\begin{array}{l}\text { Infant } \\
\text { regurgitation } \ldots \\
4 \mathbb{4}\end{array}$ \\
\hline Significant vomiting & -0.07 & 0.93 & $0.89-0.96$ & 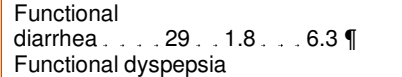 \\
\hline $\begin{array}{l}\text { Persistent right upper or } \\
\text { right lower quadrant pain }\end{array}$ & $-0 . \underline{09}$ & 0.9 & $0.82-0.95$ & 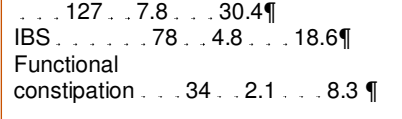 \\
\hline \multirow[t]{2}{*}{ Colonoscopy } & \multirow{2}{*}{0.27} & \multirow{2}{*}{1.21} & \multirow{2}{*}{$1.13-1.3$} & 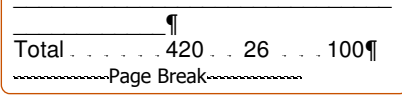 \\
\hline & & & & Deleted: 6 \\
\hline Gastrointestinal blood loss & 0.16 & 1.2 & $1.11-1.3$ & \\
\hline Chronic severe diarrhea & 0.22 & $1 . \underline{19}$ & $1.13-1.27$ & \\
\hline Persistent right upper or & 0.2 & 1.28 & $1.2-1.37$ & 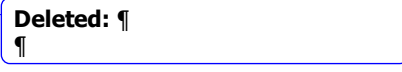 \\
\hline
\end{tabular}
right lower quadrant pain and 
Miele et al

Deleted: Figure Legend

Figure 1. A significant increase of the mean rate of the upper GI endoscopy performed for celiac

disease was observed after 1999

when the criteria were published

(42.9\% vs $21.4 \%$; $95 \% \mathrm{Cl}:-30.1$ to -

$12.7 ; p=0.004)$; no significant

difference was observed in the mean rate of the procedures performed for ulcer peptic disease $(21.7 \%$ vs

$20.6 \%$; $95 \% \mathrm{Cl}:-11.5$ to 13.6 ;

$\mathrm{p}=0.84)$; a significant decrease of the mean rate of negative upper $\mathrm{Gl}$

endoscopy was found ( $56.8 \%$ vs

$36.4 \%$; $95 \% \mathrm{Cl}: 1.3$ to $4 ; \mathrm{p}=0.006)$. ๆ

Figure 2. A significant increase of the mean rate of lower GI endoscopy for

inflammatory bowel disease was

observed when performed under the

Rome II criteria $(22.9 \%$ vs $63.9 \%$;

$95 \% \mathrm{Cl}$ : -58.6 to $-23.2 ; \mathrm{p}=0.001)$; $\mathrm{a}$

significant decrease of the mean rate

of lower endoscopy performed for GI polyps ( 18.5 vs $7.3 \%$; $95 \% \mathrm{Cl}: 0.0$ to

$22.4 ; p=0.05$ ), as well as a significant decrease of the mean rate of negative decrease of the mean rate of negative $28.7 \%$; $95 \% \mathrm{Cl}: 1.9$ to 6 ; $\mathrm{p}<0.001$ ).

Formatted: English U.S. 
Page 18: [1] Deleted Valued Acer Customer 5/21/2010 3:36:00 PM Table 1. FGIDs: Rome II Diagnostic Criteria 


\section{Infant regurgitation}

Regurgitation 2 or more times per day for 3 or more weeks

No retching, hematemesis, aspiration, apnea, failure to thrive, or abnormal posturing 1-12 mo old and otherwise healthy

No evidence of metabolic, GI, or CNS disease to explain the symptom

\section{Functional diarrhea}

For $>4$ wk, daily painless recurrent passage of 3 or more large, unformed stools, in addition to all of these characteristics:

Onset of symptoms begins between 6 and 36 mo of age

Passage of stools occurs during waking hours

No failure to thrive if adequate caloric intake

\section{Irritable Bowel Syndrome}

In children mature enough to provide an accurate pain history, at least 12 wk (need not be consecutive) within the preceding 12 months of:

Abdominal discomfort or pain that has 2 of 3 features:

Relieved with defecation

Onset associated with a change in frequency of stool

Onset associated with a change in form (appearance) or stool

There are no structural or metabolic abnormalities to explain the symptoms

\section{Cyclic vomiting syndrome}

History of 3 or more periods of intense, acute nausea and unremitting vomiting lasting hours to days, with intervening symptom-free intervals lasting weeks to months

No metabolic, GI, or CNS structural or biochemical disease to explain symptoms

\section{Functional dyspepsia}

In children mature enough to provide an accurate pain history, at least 12 wk (need not be onsecutive) within the preceding 12 months of:

Persistent or recurrent pain or discomfort centered in the upper abdomen (above the umbilicus)

No evidence (including at upper endoscopy) that organic disease is likely to explain symptoms

No evidence that dyspepsia is exclusively relieved by defecation or associated with the onset of a change in stool frequency or stool form

\section{Functional constipation}

In infants and preschool children, at least 2 wk of:

Scybalous, pebble-like, hard stools for a majority of stools

Firm stools 2 or fewer times per week

There is no evidence of structural, endocrine, or metabolic disease

\section{Functional fecal retention}

From infancy to 16 years of age, a history of at least 12 wk of:

Passage of large-diameter stools at intervals $<2$ times per week

Retentive posturing, avoiding defecation by purposefully contracting the pelvic floor; as pelvic floor muscles fatigue, the child uses the gluteal muscles, squeezing the buttocks together 
25

26

27
28

29

30

31

33

34

35

36

37

39

40

41

42
43

44

45

46

47

48

49

51

52

53

54

55

57

58

59

60 \\ Page 27 of 29}

Alimentary Pharmacology \& Therapeutic

1
2
3
4
5
6
7
8
9

1
2
3
4
5
6
7
8
9

1
2
3
4
5
6
7
8
9

10

1

3

(8)

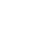

(1)

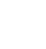

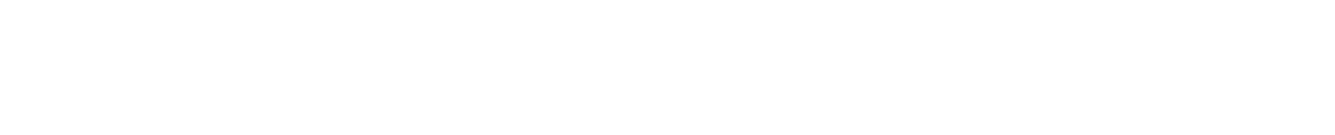

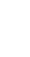

50
52
53
54
5
56
5
58
59
60


Table 1. FGIDs: Rome II Diagnostic Criteria

\section{Infant regurgitation}

Regurgitation 2 or more times per day for 3 or more weeks

No retching, hematemesis, aspiration, apnea, failure to thrive, or abnormal posturing 1-12 mo old and otherwise healthy

No evidence of metabolic, GI, or CNS disease to explain the symptom

\section{Functional diarrhea}

For $>4$ wk, daily painless recurrent passage of 3 or more large, unformed stools, in addition to all of these characteristics:

Onset of symptoms begins between 6 and 36 mo of age

Passage of stools occurs during waking hours

No failure to thrive if adequate caloric intake

\section{Irritable Bowel Syndrome}

In children mature enough to provide an accurate pain history, at least $12 \mathrm{wk}$ (need not be consecutive) within the preceding 12 months of:

Abdominal discomfort or pain that has 2 of 3 features:

Relieved with defecation

Onset associated with a change in frequency of stool

Onset associated with a change in form (appearance) or stool

There are no structural or metabolic abnormalities to explain the symptoms

\section{Cyclic vomiting syndrome}

History of 3 or more periods of intense, acute nausea and unremitting vomiting lasting hours to days, with intervening symptom-free intervals lasting weeks to months

No metabolic, GI, or CNS structural or biochemical disease to explain symptoms

\section{Functional dyspepsia}

In children mature enough to provide an accurate pain history, at least $12 \mathrm{wk}$ (need not be onsecutive) within the preceding 12 months of:

Persistent or recurrent pain or discomfort centered in the upper abdomen (above the umbilicus)

No evidence (including at upper endoscopy) that organic disease is likely to explain symptoms

No evidence that dyspepsia is exclusively relieved by defecation or associated with the onset of a change in stool frequency or stool form

\section{Functional constipation}

In infants and preschool children, at least 2 wk of:

Scybalous, pebble-like, hard stools for a majority of stools

Firm stools 2 or fewer times per week

There is no evidence of structural, endocrine, or metabolic disease

\section{Functional fecal retention}

From infancy to 16 years of age, a history of at least 12 wk of:

Passage of large-diameter stools at intervals $<2$ times per week

Retentive posturing, avoiding defecation by purposefully contracting the pelvic floor; as pelvic floor muscles fatigue, the child uses the gluteal muscles, squeezing the buttocks together 
Table 6. FGIDs in the Studied Population According to the Rome II Criteria

\begin{tabular}{llll}
\hline Disorder & $\begin{array}{l}\text { No. of } \\
\text { Children }\end{array}$ & $\begin{array}{l}\text { \% of Studied } \\
\text { Population }\end{array}$ & $\begin{array}{l}\text { \% Among } \\
\text { FGIDs }\end{array}$ \\
\hline Infant regurgitation & 152 & 9.4 & 36.4 \\
Functional diarrhea & 29 & 1.8 & 6.3 \\
Functional dyspepsia & 127 & 7.8 & 30.4 \\
IBS & 78 & 4.8 & 18.6 \\
Functional constipation & 34 & 2.1 & 8.3 \\
\hline Total & & & 100
\end{tabular}

